\title{
17 | Democratizing science in the UK: the case of radioactive waste management
}

\author{
JASON CHILVERS
}

\section{Introduction: professional networks for science and citizenship}

Despite powerful justifications, the active involvement of citizens and stakeholders within complex, uncertain environmental decision processes has occurred only very recently in the UK. This chapter draws on a study that has explored aspects of this democratization by following professional actors (participatory practitioners, scientific experts and decision-makers) through networks currently building up around participatory risk appraisal generally and specifically around radioactive waste, and engaging them in critical reflection through in-depth interviews and a workshop process (Chilvers 2004).

Key features of participatory risk appraisal have been described in recent ideal-type conceptualizations of a democratic environmental risk policy process (RCEP 1998; Stern and Fineberg 1996; see also Burns and Uberhorst 1988; Ozawa 1991). These emphasize the legitimate inclusion of citizens, stakeholders and their respective knowledges/rationalities along with the integration of analysis (science) and deliberation (participation) at all stages of the decision process, from 'front-end' framing, through assessing, to management/action. By opening up technical policy processes to extended peer review, participatory risk appraisal provides citizens with a legitimate voice in (re)negotiating (social) uncertainties/indeterminacies embedded in science (Wynne 1992), and represents a fundamental restructuring of the (power) relationship between citizens and specialists (Fischer 2000; Irwin 1995).

In the UK, there is an emergent epistemic community (Haas 1992) of professional actors with recognized competence in participatory risk appraisal practice, comprised of a core group of 'process experts' (participatory practitioners and researchers). These are engaging with decisionmaking institutions in a range of environmental risk issues in diverse locations. While fragmentation and competition currently limit social learning, actors share broadly consensual beliefs about how science should be democratized which are closely aligned with the ideal-type democratic model outlined above. ${ }^{1}$ Their principles implicitly critique many existing. participatory approaches for upholding distinctly modernist assumptions, 
being insufficiently informed by constructivist perspectives on environmental knowledge, and succumbing to what could be termed the 'technocracy of participation'.

In this context, the chapter now offers perspectives on the degree to which science is being democratized by focusing on actors' reflections on past and present practice of citizen engagement in the area of radioactive waste management.

\section{Citizen and stakeholder participation in radioactive waste policy processes}

Past practice The current regulatory system for radioactive waste management in the UK involves a separation between government, which sets national policy directions through the Department for Environment, Food and Rural Affairs (Defra), the organizations responsible for the disposal of wastes - UK Nirex Ltd (Nirex) and British Nuclear Fuels Ltd (BNFL) - and regulatory agencies (including the Environment Agency and the Nuclear Industries Inspectorate). This institutional context has its origins in the Royal Commission on Environmental Pollution's 6th Report (RCEP 1976), which recommended that a national radioactive waste disposal facility should be developed and operated by a National Waste Disposal Corporation. Nirex was established in 1982 to assume this role.

After a period of scientific research and site evaluation, Nirex announced its intention to develop a deep underground repository for radioactive waste disposal in 1988, before deciding in the early 1990 s to concentrate investigations on the suitability of Sellafield in Cumbria, for which it proposed a Rock Characterization Facility (RCF). This met considerable local and national opposition, and was refused planning permission by Cumbria County Council in 1994. Nirex appealed and a public inquiry ensued. The appeal was eventually dismissed by the Secretary of State in 1997. This represented a significant failure for Nirex, and a massive setback for the UK government in seeking a solution for the long-term management of radioactive waste.

This failure represents a defining moment in the story of radioactive waste decision-making in the UK. Prior to 1997, radioactive waste policymaking was a distinctly technocratic process, dominated by the framings of scientific experts and exclusive dialogue between government, waste management companies, regulators and other professional stakeholders deemed to have sufficient technical competence. Public involvement in decision-making was limited or non-existent (Chilvers et al. 2003; Hunt 2001), and confined to the end of policy processes after definitions, options and assessments had been framed and constrained by decision-making institutions through a strategy of decide-announce-defend (House of Lords 
1999; POST 1997). Any engagement was underpinned by a deficit model of public understanding and of citizenship that sought to educate and reassure the public that 'we know best' and 'believe us, we're scientists'. The RCF failure, however, was the crisis that forced institutions to seek help from participatory process experts.

Current practice Since 1997 , the radioactive waste participatory risk appraisal epistemic community has evolved rapidly, from tightly defined, highly separated networks around Nirex and BNFL to a more inclusive network around Defra and the UK government's Managing Radioactive Waste Safely (MRWS) process (Defra 2001). This has coincided with the rapid development of citizen and stakeholder engagement practice. In order to gauge the extent of this shift, Table $\mathbf{1 7 . 1}$ presents an analysis of the nature and extent of current participatory practice. It takes seven case examples, nominated as being particularly important or innovative actors, and assesses them against three key aspects of the ideal-type model of participatory risk appraisal outlined in the introduction: who is represented; to what extent are they engaged; and to what degree is science and participation integrated at each stage of the process?

- In terms of representation, Table $\mathbf{1 7 . 1}$ differentiates between professional stakeholders, local stakeholders and publics (after Chilvers et al. 2003; Clark et al. 2001), given differences in whom they might represent and differences in their epistemic (knowledge) and ethical (value) claims to participation. The three far-right columns of Table 17.1 provide qualitative scores of the extent of engagement and degree of integration between analysis and deliberation in the framing, assessing and evaluation stages of each nominated case. The degree of integration is assessed according to three levels:

- Low or non-interactive integration: analysis and deliberation remain separate, with no direct exchange or contestation between participants and specialists (for example, written material, remote presentations, face-toface presentations, expert Delphi processes);

- Moderate or interactive integration: direct interaction between analysis and deliberation, and direct exchange between participants and specialists in 'extended peer review' (Funtowicz and Ravetz 1993) (for example, expert panels, various forms of information communication technology);

- High or active integration: participants actively contribute 'extended facts' (Funtowicz and Ravetz 1992, 1993) and lay/experiential knowledge to analysis and/or work together with specialists in conducting 